\title{
Narrative review of the contemporary surgical treatment of unicuspid aortic valve disease
}

\author{
Maria von Stumm ${ }^{1}$, Tatjana Sequeira-Gross ${ }^{1}$, Johannes Petersen ${ }^{1}$, Shiho Naito ${ }^{1}$, Lisa Müller ${ }^{1}$, \\ Christoph Sinning ${ }^{2}$, Evaldas Girdauskas ${ }^{1}$ \\ ${ }^{1}$ Department of Cardiovascular Surgery, University Heart \& Vascular Center, University Medical Center Hamburg-Eppendorf, Hamburg, Germany; \\ ${ }^{2}$ Department of Cardiology, University Heart \& Vascular Center, University Medical Center Hamburg-Eppendorf, Hamburg, Germany \\ Contributions: (I) Conception and design: M von Stumm, E Girdauskas; (II) Administrative support: E Girdauskas; (III) Provision of study materials \\ or patients: E Girdauskas; (IV) Collection and assembly of data: M von Stumm, E Girdauskas; (V) Data analysis and interpretation: M von Stumm, E \\ Girdauskas; (VI) Manuscript writing: All authors; (VII) Final approval of manuscript: All authors. \\ Correspondence to: Maria von Stumm, MD. University Heart Center Hamburg, Martinistraße 52, 20246 Hamburg, Germany. \\ Email: m.stumm@uke.de.
}

\begin{abstract}
Unicuspid aortic valve disease (UAVD) is a frequent and long-lasting challenge for adult congenital heart disease centers. UAVD patients become usually symptomatic in their twenties or thirties and require a surgical treatment plan which should respect their complete lifespan combined with an adequate quality of life. Unfortunately, all current surgical strategies of congenital aortic valve disease bear some important limitations: (I) Aortic valve replacement using bioprosthetic valves is associated with early structural degeneration and leads frequently to re-operations. (II) Mechanical valves are commonly associated with lifelong risk of severe bleeding due to oral anticoagulation. (III) Using a pulmonary autograft (i.e., Ross procedure) for aortic valve replacement is associated with excellent long-term results in non-elderly patients. However, failure of pulmonary autograft or pulmonary homograft may require re-operations. (IV) Aortic valve repair or Ozaki procedure is only performed in a few heart centers worldwide and is associated with a limited reproducibility and early patch degeneration, suture dehiscence or increased risk of endocarditis. In contrast to degenerative tricuspid aortic valve disease, UAVD remains relatively understudied and reports on UAVD treatment are rare and usually limited to retrospective single-center observations. For this review, we searched PubMed for papers in the English language by using the search words unicuspid aortic valve, congenital aortic valve, Ross procedure, Ozaki procedure, aortic valve repair, mechanical/bioprosthetic aortic replacement, homograft. We read the abstracts of relevant titles to confirm their relevance, and the full papers were then extracted. References from extracted papers were checked for additional relevant reports. This review summarizes current surgical treatment strategies for UAVD including aortic valve replacement using bioprosthetic or mechanical valves, homografts, pulmonary autografts (i.e., Ross procedure) and aortic valve repair techniques for UAV. Furthermore, Ozaki procedure will be discussed.
\end{abstract}

Keywords: Unicuspid aortic valve disease (UAVD); congenital aortic valve disease; aortic valve repair; Ross procedure

Submitted Sep 24, 2020. Accepted for publication Dec 14, 2020.

doi: $10.21037 / \mathrm{cdt}-20-814$

View this article at: http://dx.doi.org/10.21037/cdt-20-814

\section{Introduction}

Unicuspid aortic valve disease (UAVD) in adult congenital heart disease centers remains a formidable and prolonged challenge, since UAV patients are young and surgical treatment strategies do not offer longtime durability. Unfortunately, neither the American nor the European guidelines for management of valvular heart disease elaborate on the surgical treatment strategy of UAV patients. The 

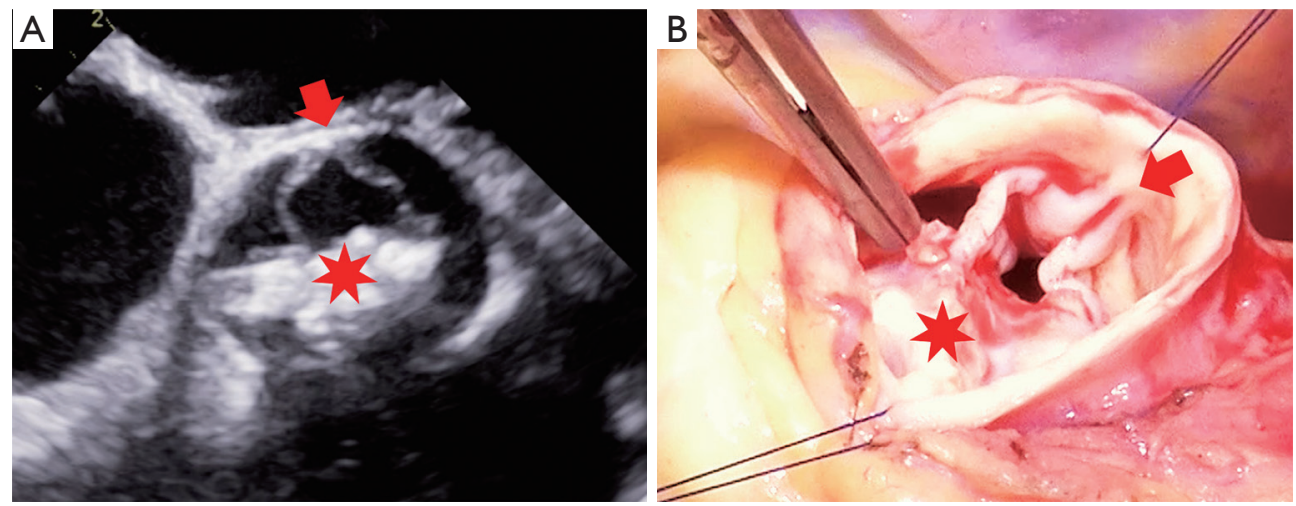

Figure 1 Intraoperative images of an unicommissural unicuspid aortic valve by transesophageal echocardiography (A) and by surgeon's view (B). The valve shows normal cusp tissue in the area of the single commissure (red arrow) and severe calcification in the region of the fused cusps (red star) resulting in a mixed AV lesion (i.e., aortic valve stenosis with concomitant aortic valve regurgitation).

Guidelines for management of adults with congenital heart disease, published by the American College of Cardiology (ACC) and American Heart Association (AHA) in 2018, give no specific treatment recommendations for UAV in their chapter of congenital valvular aortic stenosis and solely refer to the ACC/AHA Guidelines for management of patients with valvular heart disease published in $2014(1,2)$. Here, in the chapter of "Evaluation and Selection of Prosthetic valves", mechanical protheses are recommended for non-elderly patients (age $<50$ years) with severe aortic valve disease (Level IIa; Class B-NR) (2). For patients of every age with contraindication for oral anticoagulation, usage of bioprosthetic aortic valves is recommended (Class I; Level C) (2) — despite the high risk of structural valve deterioration (SVD) especially in young patients (3). As an alternative for aortic valve replacement in non-elderly patients with undesirable oral anticoagulation, pulmonary autografts (Ross procedure) are recommended when performed by an experienced surgeon (Level IIb; Class C) (2). In line with this, the Guidelines for the management of adult congenital beart disease, published 2020 by the European Society of Cardiology (ESC), mention the Ross procedure as surgical option for patients of childbearing age and for those wanting to avoid anticoagulation (4). Interestingly, there is no explicit recommendation for aortic valve repair in non-elderly patients. Though, the American and European Guidelines recommend a heart team discussion for selected patients in whom aortic valve repair may be a feasible alternative to valve replacement (Level 1, Class C) (2,5). Furthermore, aortic valve repair procedures should be concentrated in those centers with proven expertise in the procedure (2).
Therefore, the evidence on surgical treatment of UAVD is currently sparse and an operative standard is missing. In this review, we highlight benefits and disadvantages of repair and replacement methods for one-cusped aortic valves in consideration of the unique anatomy and pathophysiology of these patients. We will focus on modern technical aspects of unicuspid aortic valve (UAV) repair in adults including the concept of bicuspidalization of native cusp tissue using patch augmentation and discuss current surgical principles of the Ross procedure. At the beginning, we briefly review anatomy, prevalence, pathophysiology and associated pathologies of UAVD. We present the following article in accordance with the Narrative Review reporting checklist (available at http://dx.doi.org/10.21037/cdt-20-814).

\section{Anatomy and prevalence of UAVD}

The aortic valve consists of three components including valve cusps, commissures, and sinuses. The arrangement of these parts during embryogenesis is variable in humans and according to the number of cusps they are described as unicuspid, bicuspid, tricuspid, quadricuspid and pentacuspid aortic valves (6-8). Depending on the number of commissures, UAV are further divided into acommissural and unicommissural UAVs. An acommissural UAV is characterized by three underdeveloped, congenitally fused commissures and a "pin-hole" shaped orifice, while an unicommissural UAV presents with two underdeveloped and one normal commissure (usually located between the non-coronary and the left-coronary cusp), resulting in a slit-shaped or "fish-mouth" like orifice (Figure 1) (9). The 
genesis of UAV is not fully understood yet, whereby familiar inheritance patterns let assume genetic mechanisms. In a recent retrospective study examining 75 patients with UAV $11 \%$ of patients presented with a family history of congenital aortic valve disease (10).

Overall, UAVD represents a rare cause of aortic valve disease in adults. Based on the data from an American single-center study that examined 113,552 transthoracic echocardiographic images, UAVD was found in $0.02 \%$ in the general adult population (11).

In adults undergoing aortic valve surgery, UAVD is more commonly diagnosed with an reported prevalence of $5 \%$ (12). However, true prevalence of UAVD may be underestimated, since echocardiographic sensitivity of aortic cuspidality is limited to $40-50 \%$ (13). Even by intraoperative surgical inspection, there is still a notable likelihood of confusion between unicuspid and bicuspid aortic valves due to calcified and acquired commissural fusion (13).

\section{Pathophysiology}

In comparison to tricuspid aortic valves, the mechanical features of UAVs are deficient from birth on with a variable extent of stenotic and regurgitant components. Acommissural UAVs show almost no cusp opening during systole and are therefore accompanied by severe aortic stenosis already in early infancy. In line with this, acommissural UAVs are one of the main causes for aortic valve surgery in early childhood (9). On the contrary, unicommissural UAVs show more cusp mobility with a larger valvular opening than the acommissural valves. However, the segment of the two thickened and fused rudimentary commissures in unicommissural UAVs are prone to early calcification, while the cusp tissue in the area of the "normal" commissure remains usually pliable and functionally intact. Hence, patients with unicommissural UAVs develop severe stenosis, often combined with valvular regurgitation, in the rapid growth phase, (i.e., during early adulthood) and require surgical treatment predominantly in their third to fifth decade of life (i.e., 20-30 years earlier than for a tricuspid aortic valve) $(6,14)$.

\section{Associated pathologies}

Patients with UAV show a predisposition for aortic dilation $(10,15)$. In most cases, aortic dilation occurs at the level of ventriculo-aortic junction (VAJ) of the aortic valve, while dilation of aortic root is less commonly diagnosed (in comparison to BAV patients) (15). The exact mechanisms of aortic dilation in congenital aortic valve disease is not fully understood yet. However, post-stenotic turbulences in combination with genetic abnormalities of the aortic wall are probably the underlying cause (16).

Patients with congenital heart disease show also an increased likelihood of abnormal pulmonary valve morphology and coronary anomalies $(17,18)$. In line with this, we recommend assessment of both semilunar valves by transesophageal echocardiography, assessment of aortic dimensions by chest computed tomography and imaging of coronary arteries by coronary angiography or cardiac computed tomography before planning the surgical treatment strategy.

\section{Methods}

Until March 2020, a systematic literature search was performed on PubMed, Embase, Ovid and Google Scholar databases by using the following terms: aortic valve replacement, aortic valve repair, bicuspid aortic valve, UAV, aortic stenosis or regurgitation, adult congenital aortic valve disease, valve sparing aortic root replacement and aortic valve reconstruction. The search was limited to original adult human studies and papers which were published in English. The key inclusion criterion was that any kind aortic valve procedure was performed in UAVD associated with an aortic regurgitation or/and stenosis. After this preselection process, a manual search of the reference lists of all eligible articles was performed. Two authors (MVS and EG) assessed the methodological quality of the full-text articles prior to final inclusion in the manuscript.

\section{Treatment strategies}

Surgical UAV treatment strategies follow two basic principles: sparing the native valve and repairing it $v s$. resecting the native valve and replacing it. Since UAV patients represent a very young patients' cohort, native cusp tissue preserving techniques (i.e., valve sparing techniques/usage of autologous tissue) are considered to be much better durable in comparison to the prosthetic material. In the next sections we discuss in detail each treatment option for UAV that is currently used or under active investigation. In Table 1 we summarized our findings.

\section{Mechanical valves}

The first "mechanical valve", a caged ball-valve, was implanted into the aortic valve position in 1960 by Dr. Harken $(19,20)$. Since then, mechanical valve prostheses 
Table 1 Treatment strategies for UAV in nonelderly patients

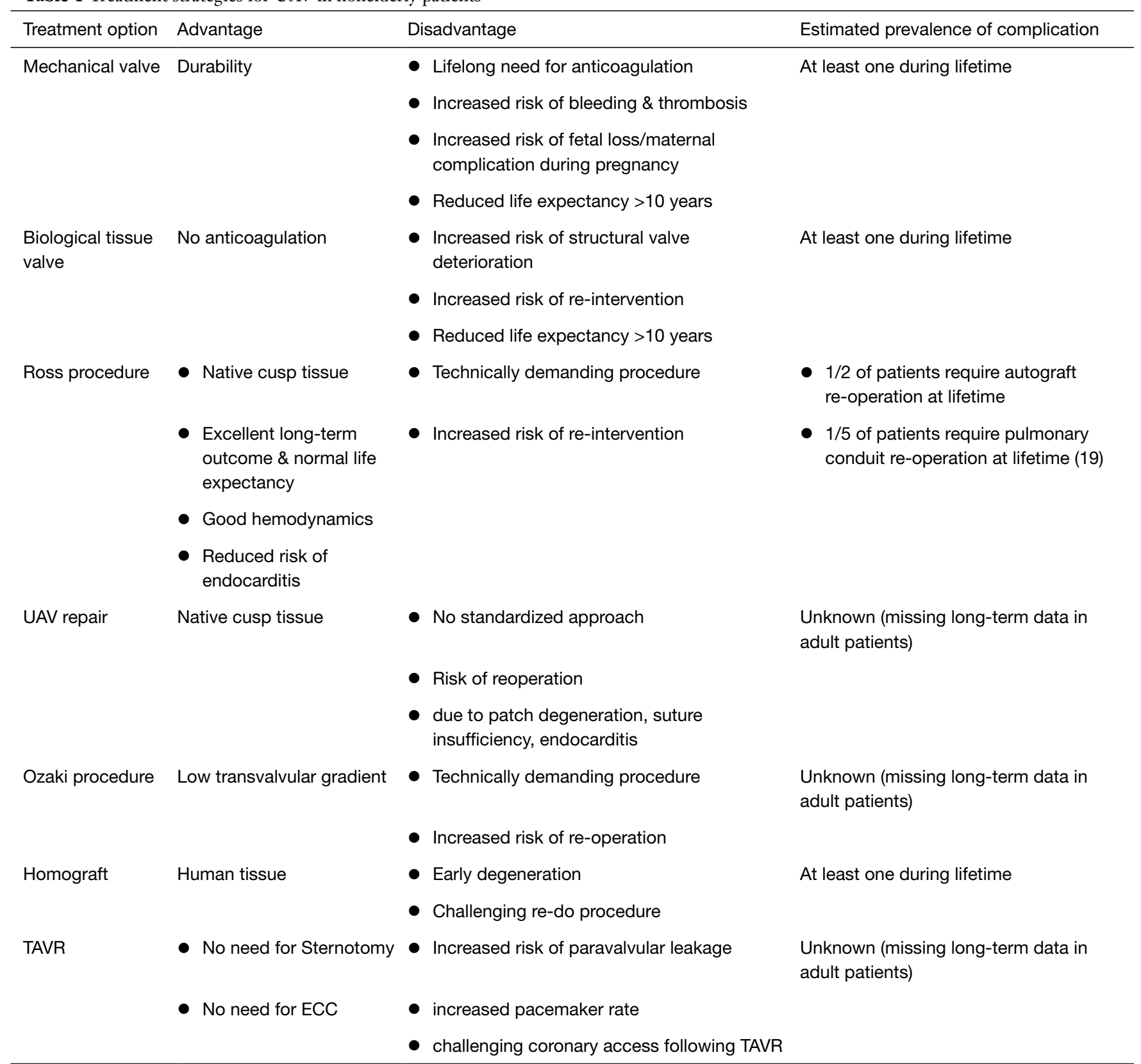

UAV, unicuspid aortic valve; TAVR, transcatheter aortic valve replacement; ECC, extracorporeal circulation.

impress with their excellent durability profile. Though, mechanical heart valves interact with the human coagulation system and life-long anticoagulation is necessary to avoid valvular thrombosis and thromboembolic complications. On the other side, anticoagulation is associated with severe bleeding complications that have a major impact on longterm survival in adults. Previously, Bouhout and coworkers published an observational study including non-elderly patients with congenital aortic valve disease who underwent an isolated mechanical aortic valve replacement (21). Their study cohort showed a twofold higher long-term mortality risk when compared to the general population $(13 \% v s$. $6 \%$ at 10 years) (21). Cumulative risk of severe prosthesisrelated complications (i.e., death, prosthesis dysfunction, endocarditis, thrombosis of the mechanical prosthesis, thromboembolic events, severe bleeding requiring 

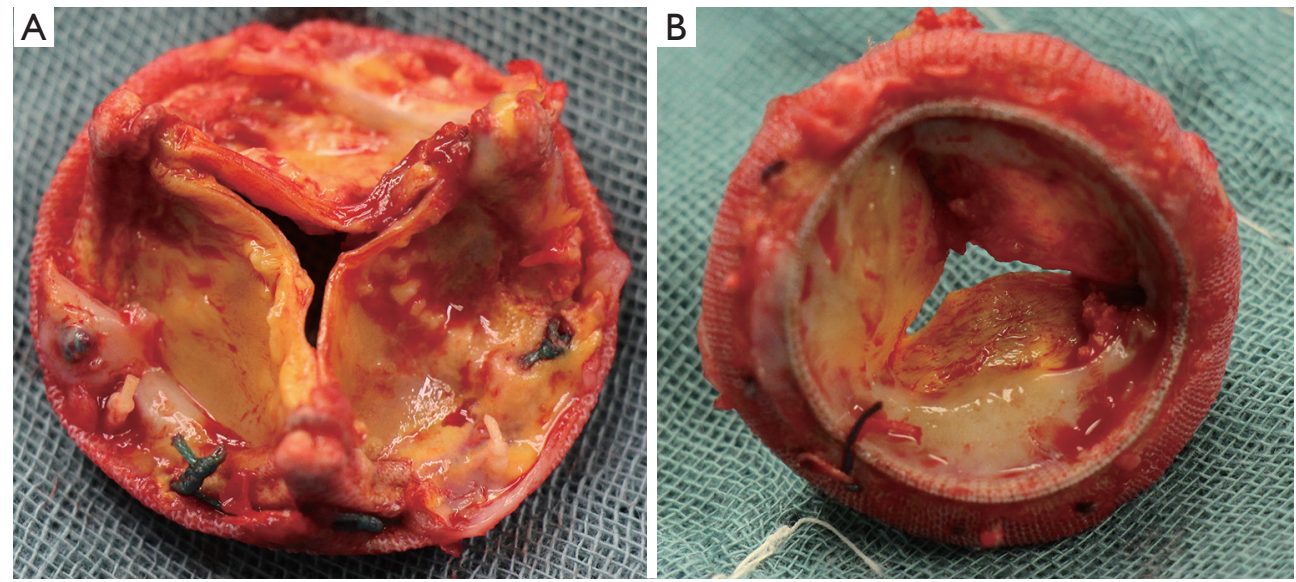

Figure 2 Images of a degenerated aortic valve bioprosthesis shortly after intraoperative resection.

hospitalization and transfusion) was $27 \%$ at 10 years (21). Furthermore, actuarial survival free from re-operation was $82 \%$ at 10 years $(21)$.

To overcome the disadvantage of bleeding complications, newer generation bileaflet mechanical valve prostheses (e.g., On-X valve) have been released over the last two decades, which allow a low-dose anticoagulant treatment (target INR 1.5-2.0). However, an explicit advantage of the low-dose anticoagulant scheme could not be demonstrated in terms of bleeding and thromboembolic complications. In the Randomized On-X Anticoagulation Trail (PROACT Trail), the linearized rate of prosthesis-associated adverse events (i.e., major bleeding, thromboembolism and thrombosis) was $4.4 \%$ per patient-year in the low-dose warfarin group compared to $5.2 \%$ in the standard warfarin group (22). In the ongoing PROACT Xa trail, apixaban could be identified as efficient modern medication in patients with an On-X aortic heart valve, which is less prone to bleeding events in comparison to warfarin (23).

With respect to the current evidence from the published literature, we conclude, that young patients with mechanical valves will suffer at least one major prosthesis-related complication during their lifetime (24). In line with this, a mechanical aortic valve substitute is a suboptimal surgical solution in patients aged $<55$ years. Especially in young patients with contraindications for oral anticoagulation (i.e., family planning women, athletes) other treatment choices should be preferred.

\section{Bioprosthetic valves}

In 1969, Marian Ionescu and Donald Ross reported their first experiences using autologous fascia-lata grafts mounted on a scallop-shaped titanium frame as a substitute for diseased heart valves (25). In 1971, Marian Ionescu improved the design and started to use glutaraldehydetreated, stent-mounted pericardial tricuspid valves for aortic valve replacement (26). The major advantage of such a "biological" valvular substitute was the avoidance of oral anticoagulation. However, there is some recent evidence on subclinical leaflet thrombosis with reduced valvular cusp motion in bioprosthetic valves and in such cases, therapeutic anticoagulation might be possibly required (27-29). Probably, the biggest drawback of bioprosthetic valves is SVD requiring surgical or catheter-based re-intervention (Figure 2). Recently, Dr Etnel and colleagues examined in a large-scaled meta-analysis with microsimulation longterm results following bioprosthetic valve implantation in the non-elderly adults aged below 55 years (3). In total, the researcher investigated outcome data of 19 studies $(\mathrm{n}=2,686$; mean age 51 years) with a pooled mean followup of 8 years. The proportion of patients with congenital aortic valve disease was $10.7 \%$. In their analysis, the median time to SVD was 17.3 years and the median time to allcause first reintervention was 16.9 years. Though, the study endpoints of SVD and re-intervention were calculated by univariate analysis without incorporating the survival status. Therefore, non-survivors were omitted in their calculation and actuarial SVD and re-intervention rates may be even worse in their study cohort.

Using a microsimulation model, the authors calculated a cumulative reduction of life expectancy of 11 years for a 45-year-old adult patient undergoing bioprosthetic aortic valve replacement, as compared to age- and sex- 
matched general population. Furthermore, the younger the patients were, the lower was their estimated life expectancy following bioprosthetic valve implantation. In contrast to this, life expectancy of elderly patients (i.e., $>65$ years) who underwent bioprosthetic aortic valve replacement was comparable with the general population with a lifetime re-intervention rate of $9 \%$. This were recently shown in a metanalysis and microsimulation from Huygens and colleagues including data of 42 studies $(n=12,842$; mean age 76.5 years) (30).

Lately, modern concepts evolved to avoid high-risk redo surgery for SVD following bioprosthetic valve implantation using transcatheter approaches with valve-in-valve transcatheter aortic valve replacement (ViV TAVR) combined with an intentional fracturing of the surgical bioprosthesis. However, most of the evidence on VIV-TAVR is derived from small-numbered retrospective self-reported registries without long-term data $(31,32)$. In general, ViV TAVR is considered to be safe, effective, and reproducible. Though, ViV TAVR has its own limitations including patientprothesis-mismatch (32\%), risk of coronary obstruction (2\%) and valve migration (4\%).

In summary, usage of bioprosthetic valves in the young and physically active patients should be considered as an absolute bail-out solution, when other surgical treatment strategies (e.g., Ross procedure) are not possible. On the other hand, in non-elderly patients with severe comorbidities a priori (i.e., cancer patients) or at very high bleeding risk, bioprosthetic valve implantation can be favored over mechanical valve implantation. Finally, VIV TAVR is a potential technique to overcome the limitations of SVD of bioprosthetic valves in high surgical risk scenarios, however, a (survival) benefit of this strategy has still to be proven.

\section{Bioprosthetic vs. mechanical valves}

In the literature, the qualities of bioprosthetic versus mechanical aortic valve substitutes were frequently analyzed. The existing evidence was previously summarized in a large-scaled meta-analysis by Zhao and other Australian researchers (33). A total of 12 studies $(n=8,661$; mean age 64 years) were included to evaluate the outcome of nonelderly patients with bioprosthetic or mechanical valves in the with a pooled mean follow-up duration of 7.5 years. Implantation of mechanical valves $v s$. bioprosthetic valves was associated with a significant survival benefit in patients aged less than 65 years (HR 1.47). Probably this was linked to the increased proportion of re-operations in the group of patients who had previously undergone bioprosthetic valve implantation (HR 2.19). With focus on risk of bleeding and anticoagulant-related events bioprosthetic valves were favored over mechanical valves (HR 0.54) (33). Recently, Goldstone and colleagues investigated the same question and examined long-term outcomes in patients who underwent primary aortic valve or mitral valve replacement with a bioprosthetic or mechanical valve in California (34). In the aortic replacement cohort $(n=9,942)$, mean followup times were 5.0 years for the bioprosthetic valve cohort ( $\mathrm{n}=3,845$; mean age 57 years) and 8.2 years for the mechanical valve cohort $(n=6,097$; mean age 56 years). In accordance to the previous findings, mechanical valves were associated with a lower long-term mortality as compared to bioprosthetic valves. However, this benefit ended at the age of 55 years. They drew similar conclusions and explained the differences in mortality by the increased proportion of re-operations in the bioprosthetic valve group (HR 2.6; age group 45-54 years) (34).

Another serious issue of mechanical and bioprosthetic valve types is patient-prosthesis mismatch (PPM). In a previous meta-analysis (34 studies; $\mathrm{n}=27.186$ ), almost every second patient $(44.2 \%)$ was categorized as having moderate or severe PPM after mechanical or bioprosthetic valve implantation (35). Furthermore, PPM was identified as an adverse effect with an impact on the all-cause and cardiac-related mortality over long-term follow-up after aortic valve replacement. In the view of some studies, the impact of PPM on postoperative survival is probably more relevant in younger patients due to their higher metabolic rate and energy requirements when compared to the older ones (36,37).

In the end, bioprosthetic and mechanical valves are far away from perfect valve substitutes for the young and physically active non-elderly patients. Both valve types are equally associated with severe drawbacks and their usage should be cautiously reconsidered.

\section{The Ross procedure}

In 1967, Donald Ross introduced the subcoronary Ross procedure, consisting of the implantation of the autologous pulmonary valve into the aortic position (38). Later, he used the pulmonary autograft as an aortic root replacement (39). Following an initial enthusiasm for the Ross procedure and its worldwide adoption during the late 1980s, the procedure became increasingly uncommon and was only performed in a few high-volume centers. This skepticism arose primarily 
due to heterogeneous results following the Ross procedure from the high $v s$. low-volume centers. In particular, early mortality was increased due to the technical complexity and a significant re-operation rate on neo-aortic valve and pulmonary conduit. Since the turn of the millennium, the growing experience in aortic valve sparing surgery and development of standardized techniques for aortic root stabilization (e.g., aortic valve annuloplasty in patients with an enlarged aortic annulus) stimulated a critical reappraisal of the Ross operation. Although, the Ross procedure accounts still for less than $0.5 \%$ of all aortic valve replacement procedures, which are registered by the STS National Database (40). Considering the benefits of using the patient's own living tissue over other suboptimal alternatives for aortic valve replacement, these low numbers of Ross procedure worldwide are worrisome. The advantages of favorable hemodynamics, low thrombogenicity, avoidance of anticoagulation, and low risk of endocarditis lead all together to excellent long-term survival rates, which have been demonstrated in several highquality studies with large sample sizes including prospective cohort studies and randomized controlled trials (41). The existing evidence on the Ross procedure was recently summarized and concentrated by the research group of Dr. Takkenberg in a meta-analysis with micro-simulation model $(41)$. Their meta-analysis included 99 studies $(n=13,129)$ reporting about Ross procedure in children (mean age 9.4 years) and adults (mean age 41.9 years) with a pooled mean follow-up of 8 years. In their pooled cohort of adults, early mortality was $2 \%$ and late mortality was $0.6 \%$ per patient-year following Ross procedure. Calculated by a microsimulation model, the lifetime risk of pulmonary autograft and right ventricular outflow tract reintervention for a 45 -year-old patient were $49 \%$ and $19 \%$, respectively. However, the amount of re-intervention showed no influence on the estimated life expectancy of patients, which was almost similar for a 45 -years-old adult following the Ross procedure (30 years) in comparison to the general population (31 years). Furthermore, the estimated life expectancy following Ross procedure was superior to all available alternatives. There is a sound clinical evidence, that the Ross procedure provides significantly better long-term results in the non-elderly patients than mechanical and bioprosthetic aortic valve replacements (42). Just recently, the group of Dr. Takkenberg published an additional micro-simulation model comparing outcomes following the Ross procedure, mechanical and bioprosthetic aortic valve replacement (42). For their calculation, they used recent data from three large-scaled systematic reviews $(3,41,43)$. By estimation of the lifetime event risk in a 45 -year-old patient, micro-simulation revealed that late mortality rates were the highest after bioprosthetic aortic valve replacement, followed by mechanical aortic valve replacement. The mortality rate following Ross procedure was significant lower. Those patients who undergo bioprosthetic or mechanical aortic valve replacement at the age of 45 years, lose 10 years of their estimated life expectancy in comparison to Ross patients. In addition, valve-related reintervention rate was the highest after bioprosthetic aortic valve replacement and slightly lower after the Ross procedure. Valve-related reintervention rate after mechanical aortic valve replacement was significantly lower compared to bioprosthetic aortic valve replacement and Ross, however, still considerable (mechanical valves $10 \%$ vs. Ross procedure 63\% vs. bioprosthetic valves $78 \%$ ). Despite an increased rate of re-operation/re-intervention following the Ross procedure, these patients show only a minimal decline in their long-term life expectancy.

Of note, center volume has a significant influence on outcome following the Ross procedure. In the literature, Charitos et al. and Tam et al. investigated the impact of high-volume hospitals on perioperative and long-term results after the Ross procedure $(44,45)$. Based on a Markov micro-simulation model using data from a single-center study of 208 propensity score matched patients (Ross procedure vs. MAVR) (46). Dr. Tam suggested that the Ross procedure should be only offered by high-volume centers that are able to perform the operation with an operative mortality $<2.5 \%$ (45). Beyond that, Charitos et al. examined the rate of reinterventions following the Ross procedure using data from the German-Dutch Ross Registry. They assessed surgical results from 13 different departments of cardiac surgery $(n=1,760)$ with a mean follow up of 7.1 years. In their analysis, center volume showed a significant influence on long-term outcomes following the Ross procedure (44). However, it remains unclear, how many Ross procedures/ year are required in a single center to achieve excellent longterm outcomes in the non-elderly patients. In our opinion, there should be at least 15 procedures/year per surgeon.

\section{Insights into the biomechanical properties of pulmonary autografts}

Over the last two decades, many physiological, biomechanical, and cellular aspects of pulmonary valves and pulmonary autograft deterioration were analyzed in the literature. In general, the native pulmonary valve differs in morphology and structure from the aortic valve and is implanted into a mechanically more demanding 
environment. Stradins et al. examined pathologically unchanged pulmonary and aortic valves of 11 cadaveric hearts (47). They demonstrated, that the native pulmonary valve cusps are thinner $(0.4 \mathrm{~mm})$ than aortic valve cusps $(0.6 \mathrm{~mm})$. However, ultimate tensile stress (i.e., maximum stress that a material can withstand) on pulmonary and aortic cusps in radial direction was practically the same. Soares and colleagues compared the performance of five cadaveric native pulmonary and aortic valves by biaxial tensile tests and by simulation of mechanical response of both valves to transvalvular aortic pressure load (48). They found that pulmonary valves are more extensible and less anisotropic due to greater collagen fibers dispersion as compared to the native aortic valves. Furthermore, due to radial deflection, there is limited coaptation area in the pulmonary valves. The limited coaptation surface of pulmonary cusps might explain the fact, that even little annulus dilatation of the pulmonary autografts leads to significant valve regurgitation.

Remodeling of the pulmonary autografts was also previously investigated. Histological assessment of explanted pulmonary autografts (range of duration since implantation from 2 weeks to 6 years) demonstrated that the structure of pulmonary valve cusps remodels toward that of the normal aortic valve (49). Moreover, pulmonary cusps maintain their functional collagen architecture and cell viability. On the contrary, histological examination of the pulmonary autograft wall revealed extensive structural tissue disruption and scarring, which was associated with a focal loss of normal smooth muscle cells, elastin, and collagen (49). In addition, Mookhoek et al. showed, that autograft walls reveal a decreased wall stiffness which results in autograft root dilatation over time (50). Potential explanation for progressive pulmonary autograft root dilatation could be iatrogenic disruption of the vasa vasorum during the surgery. They nourish the autograft wall and, therefore, may lead to scarring of the autograft wall after their disruption. Of note, the nourishment of the pulmonary valve cusps remains intact following the Ross procedure, as they are nourished by hemodynamic convection and diffusion $(51,52)$. The wellnourished cusps are one of the key elements which lead to the excellent hemodynamic flow profile of pulmonary autograft, which was recently demonstrated by Um and coworkers. The authors evaluated hemodynamic parameters following Ross vs. other (mechanical or bioprosthetic) aortic valve replacement in a meta-analysis including two randomized controlled trials and 13 observational studies $(n=1,412)(53)$. Following the Ross procedure, the mean transvalvular gradient at discharge (mean difference: $-9 \mathrm{mmHg}$ ) and at the latest follow-up (mean difference: $-5 \mathrm{mmHg}$ ) were significantly lower when compared to mechanical and bioprosthetic aortic valves. Subgroup-analysis of the two randomized controlled trials revealed an even lower mean gradient after the Ross procedure at the latest-follow-up (mean difference of $-15 \mathrm{mmHg}$ ).

Despite the growing knowledge about the qualities and properties of pulmonary autografts, many questions remain still unanswered. The exact mechanism of longterm pulmonary autograft failure (i.e., autograft dilatation) needs to be further investigated. Some of these problems can already be addressed intraoperatively during the initial implantation of the pulmonary autograft. These surgical techniques are discussed in the next section.

\section{Surgical considerations of pulmonary autograft implantation}

Currently, there are two implantation techniques used: the subcoronary $v s$. the full-root implantation technique. A recently published meta-analysis including 24 studies (subcoronary technique: $\mathrm{n}=1,355$ vs. root replacement: $\mathrm{n}=2,146$ ) compared both techniques and demonstrated similar rates of survival and freedom of re-operation (54). Contradicting these findings, in a previous analysis of the German-Dutch Ross Registry $(\mathrm{n}=1,760)$, the subcoronary technique was associated with superior pulmonary autograft durability when compared to the full-root technique (44). Today, the full-root technique is more often used, and represents surgically less complex option (54). The long-term problem of annular dilatation of the pulmonary autograft should be already addressed during the index surgery in terms of surgical aortic annular stabilization similar to patients undergoing aortic valve repair (55). Several techniques of aortic annuloplasty have been published including external suture annuloplasty using polytetrafluoroethylene (56) or ring annuloplasty using a Dacron ring (57) or Coronéo ring (58) implantation. In addition, concepts of external pulmonary autograft support using external mesh graft (59) or Dacron (60) were recently published. In our patients (unpublished data), we perform an external Dacron ring annuloplasty. Usually, we adapt VAJ size to the pulmonary autograft ring size using a 30 or $32 \mathrm{~mm}$ Dacron prosthesis strip (5 mm width) (Figure 3).

Summarizing the available evidence, the Ross procedure should currently be considered the most appropriate option for aortic valve replacement in the otherwise healthy nonelderly patients. Nonetheless, the Ross procedure is a technically demanding operation which needs to be performed in expert centers and in well-selected patients. In the UAV cohort, patients with severe stenotic, severe 

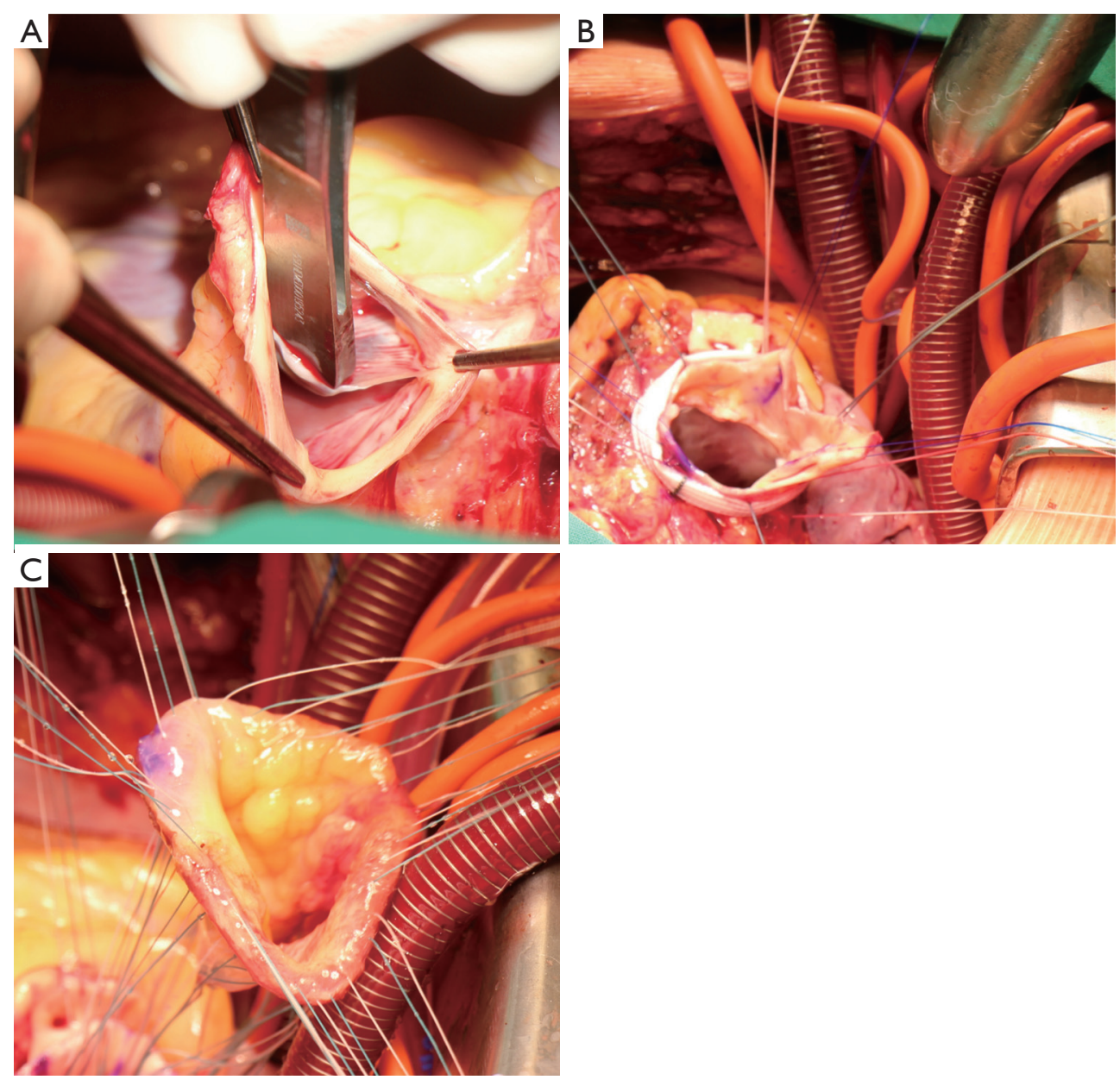

Figure 3 Intraoperative images of a Ross procedure. (A) Inspection of pulmonary valve before excision of the pulmonary autograft. (B) External annuloplasty using a Dacron graft strip and a $25 \mathrm{~mm}$ Hegar dilator. (C) Implantation of the pulmonary autograft using a single suture technique.

regurgitant or mixed type valvular pathologies are suitable to undergo the Ross procedure. Further selection criteria are lack of severe comorbidities and normal estimated life expectancy. Preoperatively, appropriate morphology and functionality of the native pulmonary valve should be reassured. Last, to avoid dilation of the pulmonary autograft on the long term, VAJ and sinotubular junction (STJ) stabilization should be routinely performed during the surgery.

\section{UAV repair}

While patients with acommissural UAVs become symptomatic in early childhood, adult patients with UAV present usually with unicommissural UAVs. In approximately every fifth case of unicommissural UAV, only the anterior portion of the valve (i.e., fused cusps) is calcified and degenerated (15). In such cases, UAV repair can be attempted by excision of the degenerated cusp tissue and subsequent cusp augmentation using autologous or xenogenic pericardium $(15,61-63)$. Of note, unicuspid valve repair without cusp augmentation or usage of additional material is only occasionally possible in a few selective cases. When UAV degeneration is more extensive and cusp calcification exceeds more than $40 \%$, aortic valve replacement including the Ross procedure should be favoured (15).

Already in 1963, Donald N. Ross treated aortic valve incompetence using cusp augmentation (64). In tricuspid aortic valves with cusp prolapse, he extended the cusp with 
a teflon felt tongue with acceptable short-term outcomes. A modern concept of aortic valve repair in one-cusped aortic valves was introduced by Schäfers et al. in 2008 (61). Their main principle of their repair was to construct a bicuspid valve with two normal commissures and unrestricted cusp motion. Just recently, they published mid-term outcomes of 137 patients (median follow-up 9 years) who underwent UAV repair between 2003 and 2014 at their institution. In 2009, Schäfers et al. modified their operative strategy with additional external suture annuloplasty in cases of VAJ dilatation. In their published cohort, freedom from aortic regurgitation $\geq$ moderate was $72 \%$ and $40 \%$ at 5 and 10 years, respectively. Freedom from aortic valve reoperation was $77 \%$ and $59 \%$ at 5 and 10 years, respectively. Aortic valve reoperation was necessary in $34 \%$ patients (in numbers: 47/137) due to patch degeneration $(n=20)$, suture dehiscence of patch $(\mathrm{n}=17)$, subaortic stenosis $(n=3)$, infective endocarditis $(n=3)$, tissue erosion with a braided polyester suture for annuloplasty $(n=2)$, aortic root dilatation $(\mathrm{n}=1)$, or unknown $(\mathrm{n}=1)$.

Interestingly, Kolesar et al., who also performed UAV repair using bicuspidization technique with equine pericardium in 17 patients, did not report any aortic valve reoperations (62). Furthermore, in their cohort, mean grade of aortic insufficiency was 0.8 at the 1 -year follow-up.

Many aspects of UAV repair are still unknown. First, it remains unclear, which patch material (i.e., autologous/bovine/ equine pericardium; synthetic material) is the most suitable for cusp augmentation. Recently, the group of El Khoury reported an unfavorable outcome in a 12-year-old boy, who underwent bicuspidalization of an UAV using a CorMatrix patch (CorMatrix Cardiovascular, Roswell, USA) (65). Already four years after $\mathrm{AV}$ repair, the patch was severely calcified. $\mathrm{AV}$ reintervention was required, and the patient underwent a Ross procedure.

Secondly, the best position and the optimal height for the newly created commissure is not defined yet. Due to differences in the biomechanical properties between native cusp tissue and patch material, suture dehiscence will remain an unpredictable problem of UAV repair. Third, surgical techniques of aortic annuloplasty vary widely and VAJ reduction strategies differ significantly between operating centers $(62,63,66)$. Since UAV repair may not be considered as a standardized technique so far, outcomes cannot be generalized. Currently, UAV repair is only performed at a few cardiac centers worldwide. In line with this, data on UAV repair consists only on single-center studies with retrospective study design and limited sample size.
In summary, there is no sufficient evidence to recommend UAV repair. Therefore, other surgical options for aortic valve replacement should be favored.

\section{Aortic valve cusp replacement}

During the 1960s few surgeons attempted single AV cusp replacement and triple cusp extension using fresh autologous pericardium in patients with aortic valve pathologies (67). However, these initial series were limited to a small number of patients and showed ambiguous results. In 1995, Duran et al. modified the technique of aortic tri-cusp replacement and published his initial experience with promising outcomes (67). Finally, in 2011, Ozaki et al. revived and standardized the surgical approach of cusp replacement, which is now called aortic valve neocuspidalisation (68). Basically, all native aortic cusps are excised and three new equally sized cusps, which are created from glutaraldehyde-treated autologous pericardium or other patch-material, are sutured directly to the aortic annulus. This technique applies to all aortic valve pathologies including aortic valve stenosis, aortic valve regurgitation and endocarditis of the aortic valve. In 2018, the group of Ozaki published his midterm results of 850 patients (including 28 patients with UAV) who underwent aortic valve neo-cuspidalisation using glutaraldehyde-treated autologous pericardium (69). Over a mean follow-up period of 4.4 years, cumulative rate of reoperation was $4.2 \%$ (in numbers $15 / 850$ patients). Indication for reoperation was predominantly infective endocarditis (13/850). Over the last years, some heart centers in Europe and US adopted the Ozaki technique and reported acceptable short-term results (70-73). However, none of these studies exceeded follow-up times of two years or included more than a hundred patients. Despite the relatively short follow-up period, re-operations were reported in all published studies, most commonly due to recurrent aortic valve regurgitation and/or endocarditis.

In summary, there is currently no sound evidence, that the Ozaki procedure will result in comparable outcomes of the Ross procedure or other well-known surgical options for aortic valve replacement. Long-term results following the Ozaki procedure in the non-elderly patients should be awaited, before one can advocate the generalization of this technique in young adult patients with congenital heart disease.

\section{Homograft}

Gordon Murray implanted the first homograft in the 
descending aorta to treat severe aortic regurgitation in 1956 (74). Six years later, in 1962, Donald Ross used for the first time a homograft as aortic valve substitute in a patient with severe aortic valve stenosis (75). Since then, homografts were exponentially used as a viable alternative for aortic valve replacement. However, quite similar to bioprosthetic valve, homograft tissue degenerates exponentially, and the longterm durability is suboptimal. Previously, Dr El-Hamamsy and coworkers investigated this issue and compared longterm durability of homograft $v s$. pulmonary autograft aortic root replacement (i.e., Ross procedure) in adults with congenital aortic valve disease in a randomized controlled trial $(\mathrm{n}=228)$ (76). The pulmonary autograft group showed significantly better rates of 10 -year actuarial survival and freedom of reoperations when compared to the homograft group (97\% and $95 \%$ vs. $83 \%$ and $82 \%$ ), respectively (76). Moreover, if homograft degenerates and re-operation is required, reoperations are technically challenging due to extensive calcification of the homograft wall (77).

In summary, homograft implantation are suboptimal substitutes for aortic valve replacement in young patients with congenital aortic valve disease and, therefore, should be avoided. The possibility of a Ross procedure should be strongly considered.

\section{Transcatheter aortic valve replacement}

In 2002 , the first successful transcatheter aortic valve replacement (TAVR) was performed by Alain Cribier for a calcified aortic stenosis in a 57-years old male patient, who presented in a cardiogenic shock and suffered from significant comorbidities with an extremely high perioperative risk (78). Since then, TAVR developed towards an effective procedure to treat aortic valve stenosis in highand intermediate surgical risk elderly patients. TAVR in BAV disease is still very controversial $(79,80)$, while experience with TAVR in UAV patients is limited to a few case reports in inoperable patients (i.e., re-do scenarios) with short-term follow-up $(81,82)$. Despite accidental success of catheterbased approach in UAV, the biomechanical characteristics of UAV do not favor transcatheter approach in general. The slit-shaped valvular orifice, asymmetrical cusp calcification and frequent anomalies of coronary artery distribution may complicate deployment of the transcatheter prothesis. The anatomical features of UAV could lead to an incomplete asymmetrical TAVR prosthesis expansion in respect to the annular line causing severe paravalvular leakage and early prosthesis degeneration (80). Use of TAVR in UAV is further limited by frequent coronary anomalies in patients with congenital aortic valve disease (18). There might be an increased risk of coronary occlusion during TAVR in UAV, since right coronary ostium is often located in the proximity of rudimentary commissure between right and noncoronary cusp. Finally, concomitant aortopathy, which are common in UAV disease, cannot be addressed during TAVR procedure.

One further aspect should be kept in mind, when considering TAVR in non-elderly patients with a congenital aortic valve stenosis. More than half of such patients will develop coronary artery disease later on and will require coronary access for diagnostic or treatment reasons following TAVR (83). Though, a selective intubation of coronary ostia after TAVR can be very challenging (depending on the prosthesis used) and straightforward intervention may be thereby impeded $(84,85)$. Moreover, there is still no reliable way to orientate the transcatheter valve according to the native commissures which would facilitate the coronary access in the future (85).

Besides the anatomical obstacles of TAVR in UAV disease, long-term data of durability and outcome of TAVR in nonelderly patients with congenital aortic valve disease are currently missing. In summary, TAVR has currently no valuable place in the treatment of congenital aortic valve disease, which is stated in the same manner in the current edition of the ESC Guidelines for the management of adult congenital heart disease (4).

\section{Conclusions}

In summary, the choice of surgical treatment strategy must be discussed extensively with the patient and tailored to its individual needs, according to the relative or absolute contraindications for oral anticoagulation, taking into account family planning, elite athletes and other professionals with increased risk of bleeding injuries (i.e., firefighters, military personnel). As a general rule, normal life expectancy, freedom of symptoms and good quality of life should be aimed when planning the surgical treatment strategy.

\section{Acknowledgments}

Funding: None.

\section{Footnote}

Provenance and Peer Review: This article was commissioned 
by the Guest Editors (Yskert von Kodolitsch, Harald Kaemmerer, Koichiro Niwa) for the series "Current Management Aspects in Adult Congenital Heart Disease (ACHD): Part III" published in Cardiovascular Diagnosis and Therapy. The article has undergone external peer review.

Reporting Checklist: The authors have completed the Narrative Review reporting checklist. Available at http:// dx.doi.org/10.21037/cdt-20-814

Conflicts of Interest: All authors have completed the ICMJE uniform disclosure form (available at http:// dx.doi.org/10.21037/cdt-20-814). The series "Current Management Aspects in Adult Congenital Heart Disease (ACHD): Part III" was commissioned by the editorial office without any funding or sponsorship. The authors have no other conflicts of interest to declare.

Ethical Statement: The authors are accountable for all aspects of the work in ensuring that questions related to the accuracy or integrity of any part of the work are appropriately investigated and resolved.

Open Access Statement: This is an Open Access article distributed in accordance with the Creative Commons Attribution-NonCommercial-NoDerivs 4.0 International License (CC BY-NC-ND 4.0), which permits the noncommercial replication and distribution of the article with the strict proviso that no changes or edits are made and the original work is properly cited (including links to both the formal publication through the relevant DOI and the license). See: https://creativecommons.org/licenses/by-nc-nd/4.0/.

\section{References}

1. Stout KK, Daniels CJ, Aboulhosn JA, et al. 2018 AHA/ ACC Guideline for the Management of Adults With Congenital Heart Disease: A Report of the American College of Cardiology/American Heart Association Task Force on Clinical Practice Guidelines. J Am Coll Cardiol 2019;73:e81-192.

2. Nishimura RA, Otto CM, Bonow RO, et al. 2014 AHA/ ACC guideline for the management of patients with valvular heart disease: a report of the American College of Cardiology/American Heart Association Task Force on Practice Guidelines. J Thorac Cardiovasc Surg 2014;148:e1-e132. Erratum in: J Thorac Cardiovasc Surg 2014;64:1763.
3. Etnel JRG, Huygens SA, Grashuis P, et al. Bioprosthetic Aortic Valve Replacement in Nonelderly Adults: A Systematic Review, Meta-Analysis, Microsimulation. Circ Cardiovasc Qual Outcomes 2019;12:e005481.

4. Baumgartner H, De Backer J, Babu-Narayan SV, et al. 2020 ESC Guidelines for the management of adult congenital heart disease. Eur Heart J 2021;42:563-645.

5. Baumgartner H, Falk V, Bax JJ, et al. 2017 ESC/EACTS Guidelines for the management of valvular heart disease. European Heart Journal 2017;38:2739-91.

6. Roberts WC. The structure of the aortic valve in clinically isolated aortic stenosis: an autopsy study of 162 patients over 15 years of age. Circulation 1970;42:91-7.

7. Tsugu T, Murata M, Endo J, et al. Long-term outcomes in 3 cases of quadricuspid aortic valve, using a new classification system: A case series and literature review. Echocardiography 2019;36:595-7.

8. Tutarel O. The pentacuspid aortic valve. Ann Thorac Surg 2011;91:646.

9. Mookadam F, Thota VR, Lopez AM, et al. Unicuspid aortic valve in children: a systematic review spanning four decades. J Heart Valve Dis 2010;19:678-83.

10. Slostad BD, Witt CM, O'Leary PW, et al. Unicuspid Aortic Valve: Demographics, Comorbidities, Echocardiographic Features, and Long-Term Outcomes. Circulation 2019;140:1853-5.

11. Novaro GM, Mishra M, Griffin BP. Incidence and echocardiographic features of congenital unicuspid aortic valve in an adult population. J Heart Valve Dis 2003;12:674-8.

12. Al-Sehly AA, Robinson JL, Lee BE, et al. Pediatric poststernotomy mediastinitis. Ann Thorac Surg 2005;80:2314-20.

13. Slostad BD, Witt CM, O'Leary PW, et al. Diagnostic Accuracy of Echocardiography and Intraoperative Surgical Inspection of the Unicuspid Aortic Valve. Am J Cardiol 2019;123:967-71.

14. Mookadam F, Thota VR, Garcia-Lopez AM, et al. Unicuspid aortic valve in adults: a systematic review. J Heart Valve Dis 2010;19:79-85.

15. Noly PE, Basmadjian L, Bouhout I, et al. New Insights Into Unicuspid Aortic Valve Disease in Adults: Not Just a Subtype of Bicuspid Aortic Valves. Can J Cardiol 2016;32:110-6.

16. Robicsek F, Madjarov JM, Padera RF Jr. Cause of Ascending Aortic Dilatation in Patients with Bicuspid Aortic Valves: The Final Link. Thorac Cardiovasc Surg 2020;68:277-80. 
17. Koenraadt WMC, Bartelings MM, Gittenberger-de Groot AC, et al. Pulmonary Valve Morphology in Patients with Bicuspid Aortic Valves. Pediatr Cardiol 2018;39:690-4.

18. Naito S, Petersen J, Reichenspurner H, et al. The impact of coronary anomalies on the outcome in aortic valve surgery: comparison of bicuspid aortic valve versus tricuspid aortic valve morphotype. Interact Cardiovasc Thorac Surg 2018;26:617-22.

19. Harken DE, Taylor WJ, Lefemine AA, et al. Aortic valve replacement with a caged ball valve. Am J Cardiol 1962;9:292-9.

20. Gott VL, Alejo DE, Cameron DE. Mechanical heart valves: 50 years of evolution. Ann Thorac Surg 2003;76:S2230-9.

21. Bouhout I, Stevens LM, Mazine A, et al. Long-term outcomes after elective isolated mechanical aortic valve replacement in young adults. J Thorac Cardiovasc Surg 2014;148:1341-6.e1.

22. Puskas J, Gerdisch M, Nichols D, et al. Reduced anticoagulation after mechanical aortic valve replacement: interim results from the prospective randomized on-X valve anticoagulation clinical trial randomized Food and Drug Administration investigational device exemption trial. J Thorac Cardiovasc Surg 2014;147:1202-10; discussion 1210-1.

23. Jawitz OK, Wang TY, Lopes RD, et al. Rationale and design of PROACT Xa: A randomized, multicenter, openlabel, clinical trial to evaluate the efficacy and safety of apixaban versus warfarin in patients with a mechanical On-X Aortic Heart Valve. Am Heart J 2020;227:91-9.

24. Mazine A, Ouzounian M. Aortic valve replacement in young and middle-aged adults: looking beyond the tree that hides the forest. Ann Transl Med 2017;5:92.

25. Ionescu MI, Ross DN. Heart-valve replacement with autologous fascia lata. Lancet 1969;2:335-8.

26. Ionescu MI, Pakrashi BC, Holden MP, et al. Results of aortic valve replacement with frame-supported fascia lata and pericardial grafts. J Thorac Cardiovasc Surg 1972;64:340-53.

27. Makkar RR, Fontana G, Jilaihawi H, et al. Possible Subclinical Leaflet Thrombosis in Bioprosthetic Aortic Valves. N Engl J Med 2015;373:2015-24.

28. Sondergaard L, De Backer O, Kofoed KF, et al. Natural history of subclinical leaflet thrombosis affecting motion in bioprosthetic aortic valves. Eur Heart J 2017;38:2201-7.

29. Chakravarty T, Sondergaard L, Friedman J, et al. Subclinical leaflet thrombosis in surgical and transcatheter bioprosthetic aortic valves: an observational study. Lancet
2017;389:2383-92.

30. Huygens SA, Etnel JRG, Hanif M, et al. Bioprosthetic aortic valve replacement in elderly patients: Metaanalysis and microsimulation. J Thorac Cardiovasc Surg 2019;157:2189-97.e14.

31. Aziz M, Simonato M, Webb JG, et al. Mortality prediction after transcatheter treatment of failed bioprosthetic aortic valves utilizing various international scoring systems: Insights from the Valve-in-Valve International Data (VIVID). Catheter Cardiovasc Interv 2018;92:1163-70.

32. Dvir D, Webb JG, Bleiziffer S, et al. Transcatheter aortic valve implantation in failed bioprosthetic surgical valves. JAMA 2014;312:162-70.

33. Zhao DF, Seco M, Wu JJ, et al. Mechanical Versus Bioprosthetic Aortic Valve Replacement in Middle-Aged Adults: A Systematic Review and Meta-Analysis. Ann Thorac Surg 2016;102:315-27.

34. Goldstone AB, Chiu P, Baiocchi M, et al. Mechanical or Biologic Prostheses for Aortic-Valve and Mitral-Valve Replacement. N Engl J Med 2017;377:1847-57.

35. Head SJ, Mokhles MM, Osnabrugge RL, et al. The impact of prosthesis-patient mismatch on long-term survival after aortic valve replacement: a systematic review and meta-analysis of 34 observational studies comprising 27186 patients with 133141 patient-years. Eur Heart J 2012;33:1518-29.

36. Moon MR, Pasque MK, Munfakh NA, et al. Prosthesispatient mismatch after aortic valve replacement: impact of age and body size on late survival. Ann Thorac Surg 2006;81:481-8; discussion 489.

37. Mohty D, Dumesnil JG, Echahidi N, et al. Impact of prosthesis-patient mismatch on long-term survival after aortic valve replacement: influence of age, obesity, and left ventricular dysfunction. J Am Coll Cardiol 2009;53:39-47.

38. Ross DN. Replacement of aortic and mitral valves with a pulmonary autograft. Lancet 1967;2:956-8.

39. Chambers JC, Somerville J, Stone S, et al. Pulmonary autograft procedure for aortic valve disease: long-term results of the pioneer series. Circulation 1997;96:2206-14.

40. Reece TB, Welke KF, O'Brien S, et al. Rethinking the ross procedure in adults. Ann Thorac Surg 2014;97:175-81.

41. Etnel JRG, Grashuis P, Huygens SA, et al. The Ross Procedure: A Systematic Review, Meta-Analysis, and Microsimulation. Circ Cardiovasc Qual Outcomes 2018;11:e004748.

42. Gökalp AL, de Heer F, Etnel JRG, et al. Clinical and quality of life outcomes after aortic valve replacement and aortic root surgery in adult patients $<65$ years old. Ann 
Cardiothorac Surg 2019;8:372.

43. Mazine A, Rocha RV, El-Hamamsy I, et al. Ross Procedure vs Mechanical Aortic Valve Replacement in Adults: A Systematic Review and Meta-analysis. JAMA Cardiol 2018;3:978-87.

44. Charitos EI, Takkenberg JJ, Hanke T, et al. Reoperations on the pulmonary autograft and pulmonary homograft after the Ross procedure: An update on the German Dutch Ross Registry. J Thorac Cardiovasc Surg 2012;144:813-21; discussion 821-3.

45. Tam DY, Wijeysundera HC, Ouzounian M, et al. The Ross procedure versus mechanical aortic valve replacement in young patients: a decision analysis. Eur J Cardiothorac Surg 2019;5 5:1180-6.

46. Mazine A, David TE, Rao V, et al. Long-Term Outcomes of the Ross Procedure Versus Mechanical Aortic Valve Replacement: Propensity-Matched Cohort Study. Circulation 2016;134:576-85

47. Stradins P, Lacis R, Ozolanta I, et al. Comparison of biomechanical and structural properties between human aortic and pulmonary valve. Eur J Cardiothorac Surg 2004;26:634-9.

48. Soares AL, van Geemen D, van den Bogaerdt AJ, et al. Mechanics of the pulmonary valve in the aortic position. J Mech Behav Biomed Mater 2014;29:557-67.

49. Rabkin-Aikawa E, Aikawa M, Farber M, et al. Clinical pulmonary autograft valves: pathologic evidence of adaptive remodeling in the aortic site. J Thorac Cardiovasc Surg 2004;128:552-61.

50. Mookhoek A, Krishnan K, Chitsaz S, et al. Biomechanics of Failed Pulmonary Autografts Compared With Normal Pulmonary Roots. Ann Thorac Surg 2016;102:1996-2002.

51. Butcher JT, Mahler GJ, Hockaday LA. Aortic valve disease and treatment: the need for naturally engineered solutions. Adv Drug Deliv Rev 2011;63:242-68.

52. Weind KL, Ellis CG, Boughner DR. The aortic valve blood supply. J Heart Valve Dis 2000;9:1-7; discussion 7-8.

53. Um KJ, McClure GR, Belley-Cote EP, et al. Hemodynamic outcomes of the Ross procedure versus other aortic valve replacement: a systematic review and meta-analysis. J Cardiovasc Surg (Torino) 2018;59:462-70.

54. Berdajs DA, Muradbegovic M, Haselbach D, et al. Ross procedure: is the root replacement technique superior to the sub-coronary implantation technique? Long-term results. Eur J Cardiothorac Surg 2014;46:944-51.

55. Petersen J, Girdauskas E. Aortic valve repair-lessons to be learned. Ann Transl Med 2017;5:356.

56. Schneider U, Aicher D, Miura Y, et al. Suture
Annuloplasty in Aortic Valve Repair. Ann Thorac Surg 2016;101:783-5.

57. Basmadjian L, Basmadjian AJ, Stevens LM, et al. Early results of extra-aortic annuloplasty ring implantation on aortic annular dimensions. J Thorac Cardiovasc Surg 2016;151:1280-5.e1.

58. Vojacek J, Spatenka J, Holubec T, et al. Coroneo extraaortic annuloplasty ring could stabilize even the pulmonary autograft annulus in a Ross operation. Eur J Cardiothorac Surg 2013;43:431-3.

59. Vanderveken E, Vastmans J, Verbelen T, et al. Reinforcing the pulmonary artery autograft in the aortic position with a textile mesh: a histological evaluation. Interact Cardiovasc Thorac Surg 2018;27:566-73.

60. Ratschiller T, Sames-Dolzer E, Schimetta W, et al. External Prosthetic Reinforcement of the Pulmonary Autograft. Thorac Cardiovasc Surg 2019;67:14-20.

61. Schäfers HJ, Aicher D, Riodionycheva S, et al. Bicuspidization of the unicuspid aortic valve: a new reconstructive approach. Ann Thorac Surg 2008;85:2012-8.

62. Kolesar A, Toporcer T, Bajmoczi M, et al. Aortic Valve Repair of a Stenotic Unicuspid Aortic Valve in Young Patients. Ann Thorac Surg 2018;105:1351-6.

63. Igarashi T, Matsushima S, Shimizu A, et al. Bicuspidization and Annuloplasty Provide a Functioning Configuration to the Unicuspid Aortic Valve. Ann Thorac Surg 2020;110:111-9.

64. Ross DN. Surgical reconstruction of the aortic valve. Lancet 1963;1:571-4.

65. Mosala Nezhad Z, Baldin P, Poncelet A, et al. Calcific Degeneration of CorMatrix 4 Years After Bicuspidization of Unicuspid Aortic Valve. Ann Thorac Surg 2017;104:e431-3.

66. Komiya T. Aortic valve repair update. Gen Thorac Cardiovasc Surg 2015;63:309-19.

67. Duran CM, Gometza B, Kumar N, et al. Aortic valve replacement with freehand autologous pericardium. J Thorac Cardiovasc Surg 1995;110:511-6.

68. Ozaki S, Kawase I, Yamashita H, et al. Aortic valve reconstruction using self-developed aortic valve plasty system in aortic valve disease. Interact Cardiovasc Thorac Surg 2011;12:550-3.

69. Ozaki S, Kawase I, Yamashita H, et al. Midterm outcomes after aortic valve neocuspidization with glutaraldehydetreated autologous pericardium. J Thorac Cardiovasc Surg 2018;155:2379-87.

70. Krane M, Boehm J, Prinzing A, et al. Excellent Hemodynamic Performance After Aortic Valve 
Neocuspidization Using Autologous Pericardium. Ann Thorac Surg 2021;111:126-33.

71. Reuthebuch O, Koechlin L, Schurr U, et al. Aortic valve replacement using autologous pericardium: single centre experience with the Ozaki technique. Swiss Med Wkly 2018;148:w14591.

72. Mourad F, Shehada SE, Lubarski J, et al. Aortic valve construction using pericardial tissue: short-term singlecentre outcomes. Interact Cardiovasc Thorac Surg 2019;28:183-90.

73. Marathe SP, Chavez M, Sleeper LA, et al. Modified Ozaki procedure including annular enlargement for small aortic annuli in young patients. Ann Thorac Surg 2020;110:1364-71.

74. Murray G. Homologous aortic-valve-segment transplants as surgical treatment for aortic and mitral insufficiency. Angiology 1956;7:466-71.

75. Ross DN. Homograft replacement of the aortic valve. Lancet 1962;2:487.

76. El-Hamamsy I, Eryigit Z, Stevens LM, et al. Longterm outcomes after autograft versus homograft aortic root replacement in adults with aortic valve disease: a randomised controlled trial. Lancet 2010;376:524-31.

77. Kumar P, Athanasiou T, Ali A, et al. Re-do aortic valve replacement: does a previous homograft influence the operative outcome? J Heart Valve Dis 2004;13:904-12; discussion 12-3.

78. Cribier A, Eltchaninoff $\mathrm{H}$, Bash A, et al. Percutaneous transcatheter implantation of an aortic valve prosthesis

Cite this article as: von Stumm M, Sequeira-Gross T, Petersen J, Naito S, Müller L, Sinning C, Girdauskas E. Narrative review of the contemporary surgical treatment of unicuspid aortic valve disease. Cardiovasc Diagn Ther 2021;11(2):503-517. doi: $10.21037 /$ cdt-20-814 for calcific aortic stenosis: first human case description. Circulation 2002;106:3006-8.

79. Yoon SH, Lefevre T, Ahn JM, et al. Transcatheter Aortic Valve Replacement With Early- and New-Generation Devices in Bicuspid Aortic Valve Stenosis. J Am Coll Cardiol 2016;68:1195-205.

80. Reddy G, Wang Z, Nishimura RA, et al. Transcatheter aortic valve replacement for stenotic bicuspid aortic valves: Systematic review and meta analyses of observational studies. Catheter Cardiovasc Interv 2018;91:975-83.

81. Acharji S, Agnihotri A, Carrozza J. Transcatheter aortic valve replacement in unicuspid aortic valve stenosis. Catheter Cardiovasc Interv 2017;90:169-72.

82. Nascimbene A, Loyalka P, Gregoric ID, et al. Transcatheter Aortic Valve Implantation in a Patient with Unicuspid Aortic Valve. Tex Heart Inst J 2017;44:127-30.

83. Virani SS, Alonso A, Benjamin EJ, et al. Heart Disease and Stroke Statistics-2020 Update: A Report From the American Heart Association. Circulation 2020;141:e139-596.

84. Blumenstein J, Kim WK, Liebetrau C, et al. Challenges of coronary angiography and intervention in patients previously treated by TAVI. Clin Res Cardiol 2015;104:632-9.

85. Yudi MB, Sharma SK, Tang GHL, et al. Coronary Angiography and Percutaneous Coronary Intervention After Transcatheter Aortic Valve Replacement. J Am Coll Cardiol 2018;71:1360-78. 